\title{
Perceptions of Teachers and Parents on the Educational Experiences of Students with Autism in a Remote Rural Community
}

\author{
Amy Price Azano \\ Virginia Tech
}

\author{
Mary Elizabeth Tackett \\ Sweet Briar College
}

While the number of children diagnosed with autism spectrum disorder (ASD) continues to rise, research addressing the unique educational experiences of students with ASD in rural communities remains limited and inconclusive. This study investigates how the rural context influences the educational experiences of students with ASD. The researchers used an online questionnaire and in-person interviews of special education teachers, general education teachers, and parents to collect their perceptions of the experiences for students with ASD living in a remote rural Appalachian community. Data generation and analysis led to the discussion of three salient themes: limited parental knowledge, lack of resources and need for professional development, and low socioeconomic status and family or community structures. The authors discuss how these findings manifest in rural communities and make suggestions for further research and professional development.

The unique characteristics of rural schooling attributed to geographic isolation and infrastructural challenges have long been noted in the literature on rural education (Biddle \& Azano, 2016). Issues of rural teacher recruitment and retention, curricular needs of rural students, and under resourced schools are common inroads of scholarly inquiry for rural education researchers. However, there remains a need to explore emerging topics related to rural schooling and to understand how place and spatiality continue to influence the context for educational experiences in rural communities. The rising prevalence of autism is one such emerging topic. According to the Center for Disease Control and Prevention (CDC), a ten year, exponential increase in diagnoses has led to one in every 68 children currently being identified as having Autism Spectrum Disorder (ASD). The Diagnostic and Statistical Manual of Mental Disorders - Fifth Edition (DSM-V; American Psychiatric Association, 2013) defines ASD as a developmental disorder consisting of two core characteristics, which include (a) social and communicative deficits, and (b) repetitive and atypical behaviors. The increase in the rate of autism and the push for inclusion represent potential challenges for rural schools, teachers, and students.

On average, over $30 \%$ of the schools in the United States are rural (Johnson, Showalter, Klein, \& Lester, 2014), and areas like Appalachia contain some of the highest levels of disability in the country. At a $19.9 \%$ incidence rate, the state of West Virginia held the highest rate of disability in the nation in
2014, and Pike County, Kentucky held the highest national rate of disability (28.1\%) for counties with populations of 65,000 or more (2014 United States Census). Additionally, many families in these rural areas experience poverty (Pennington, et al., 2013), and lower income levels may intensify challenges associated with disabilities (Mandell, Novak, \& Zubritsky, 2005).

Research regarding how geographic location influences the experiences of students with ASD is thin and inconclusive. However, the increasing prevalence of disabilities and compounding contextual factors specific to rural areas present a need for examining the perceptions and experiences of parents, teachers, and children with ASD in these locations. Therefore, the purpose of this study is to better understand how the rural context influences the educational experiences for students with ASD.

Diagnosis and Treatment for ASD in Rural Areas

Due to the remoteness of many rural areas, diagnosis and treatment for ASD can be challenging. When compared to urban prevalence rates, lower incidence of rural ASD has been noted in studies exploring geographical variation (Lauritsen et al., 2014); however, this discrepancy can be attributed to diagnostic patterns or physical access to facilities that screen for ASD (Williams et al., 2006). Blane and Bordon (2008) suggest that accessing a cohort of professionals who can provide early identification and treatment is a critical initial step toward cultivating continuing developmental growth for 
children with ASD. Yet, when compared to more urban areas, children with ASD in rural areas are more likely to incur later identification and diagnosis of the disorder (Mandell, Novak, \& Zubritsky, 2005). Additionally, families living in rural areas may also lack geographic access to services (Kiani et al., 2013). So, while some studies suggest urban areas may have higher instances of ASD, they also recognize that rural areas have less access and available options for services and treatment when compared to these areas (Chen, Liu, Su, Huang, \& Lim 2008). These unique, geographic challenges result in later diagnoses and implementation of related services for students with ASD in remote rural areas. In Appalachia, these issues may be even more pronounced as the region has higher poverty levels, is medically underserved, and has weakened access to health insurance when compared to other areas in the U.S. (Behringer \& Friedell, 2006; Haverson, Ma, \& Harner, 2004).

Furthering the stress that an initial ASD diagnosis places on family structures (Hutton \& Caron, 2005), parents of children with ASD in rural areas also experience difficulties finding healthcare providers and securing early treatment and services for their children, which points to a pervasive need to improve early identification initiatives in these areas (Edwards, Gallagher, \& Green, 2013). In addition to socioeconomic status, lack of awareness, and healthcare challenges, other cultural factors in rural communities influencing diagnosis and treatment of ASD have been noted, such as stoicism and traditionalism (Kiani et al., 2013) and a distrust of professional labels and titles (Bates et al., 2014). Pennington, et al. (2013) noted "there is no doubt that the Internet and the use of electronic media has significantly impacted the disability community" ( $p$. 4) by way of providing access to information and training on ASD, but for families living in rural areas, access to online information about ASD may be limited. While acknowledging how rurality may present unique challenges for treatment and the securing of services for children with ASD, some researchers argue that these difficulties are not specific to rural areas alone (Murphy \& Ruble, 2012). This inconsistency and lack of understanding point to the need for further research aimed at understanding the perceptions and experiences of those living with ASD in rural areas.

\section{Meeting the Needs of Students with ASD in Rural Schools}

While a later diagnosis in a geographically isolated area might present unique challenges for families who have children with ASD, research indicates that accessing treatment and special services for students once they enter school may be equally challenging. In accordance with the Individuals with Disabilities Education Act (IDEA), students with ASD have the right to appropriate educational experiences and services. However, 98\% of schools across the country are experiencing difficulties staffing special education positions (Eric, 2001), and while this disparity affects both urban and rural schools, rural areas face contextually unique challenges in this area.

Rural schools have long dealt with specific challenges for recruiting and retaining teachers (Biddle \& Azano, 2016), and rural school districts are finding it increasingly difficult to hire and retain highly qualified educators and professionals who specialize in ASD, and who can provide the necessary services and treatments for students with the disability (Pennington, Horn, \& Berrong, 2009). Less competitive salaries, under resourced programs, and a lack of inclusive policies may discourage educators from teaching in rural areas (Pennington, et al., 2009), resulting in limited access to services for children with ASD when compared to more urban locations. Further confounding these perceived challenges for teaching in rural areas are the geographic isolation and the lack of recreational and professional opportunities experienced by teachers (Iringa-Bistolas, et al., 2007). However, perhaps as a result of these under resourced and geographically remote special education programs, Jung and Bradley (2006) noted that rural areas were far more likely to utilize inclusive practices when compared to more urban areas, although this disparity also attributed to a lack of communication and collaboration among special education teachers and parents when compared to more urban settings.

Conversely, some educators feel that when compared to their urban counterparts, rural areas offer children with ASD an advantage, as students may receive more individualized services and support from personnel in smaller schools and communities, resulting in quality educational opportunities for students with disabilities, even in the face of obstacles and challenges (Pennington, et al., 2009). Additionally, researchers indicate challenges 
associated with special services and treatment programs are widely expressed in both rural and urban contexts (Murphy \& Ruble, 2012). The need for parsing specific rural challenges may offer some insight into place-based, rural initiatives designed to increase supports for rural students with ASD.

\section{The Need for Professional Collaboration and Support in Rural Schools}

In order to effectively provide specialized intervention services and equitable access to quality services, resources, and professionals for rural students with ASD, a greater understanding of the unique educational experiences of students with ASD in rural communities is needed. In general, there is limited research on how teacher knowledge, training, and perceptions influence effective classroom instruction for students with ASD. Many educators lack the general knowledge and experience needed to appropriately instruct students with ASD

(Syriopoulou-Delli, Cassimos, Tripsianis, \& Polychronopoulou, 2012), contributing to a disconnect between specialists, general educators, and school leadership, which may hinder inclusive practices. However, providing adequate, professional experiences and training for educators can result in more positive perceptions toward ASD and a willingness to support special services within the classroom (Syriopoulou-Delli et al., 2012).

With the dramatic rise in autism over the last decade, schools will need to examine their policies and practices around inclusion and other services targeting the ASD population. Inclusion practices, for example, have far-reaching influence not only for students with ASD but also for general education teachers and administrators. Principals with prior training and ASD-related experiences demonstrated a commitment to inclusion and higher-level placements for students with ASD, particularly in the elementary grades (Horrocks, White, \& Roberts; 2008).

However, tenured principals may have more negative views toward inclusion and lower class placements, perhaps as a result of outdated pedagogy or lack of professional or personal experience with inclusion (Horrocks, et al., 2008). In other studies (see Rude et al., 2005), educators have highlighted a need for stronger administrative support to effectively create inclusive settings, and have indicated a desire for further training on autism and greater parental advocacy and collaboration.

\footnotetext{
${ }^{1}$ All names of people and places are pseudonyms.
}

It is critical that educators understand the intersectionality of autism and rurality. Rural students may be receiving late diagnoses or have limited access to services and treatment. Rural schools may be under resourced for providing students with ASD services assumed in metro centric, urban-biased evidence based practice but lacking in the realities of rural communities. Therefore, we asked: How does rurality and the rural context influence parents' and teachers' perceptions of the learning experiences and opportunities for students with ASD?

\section{Methods}

A year prior to this study, Amy was invited to Liberty County Public Schools ${ }^{10}$ to provide staff development about ASD to district personnel. In doing so, a special education teacher in the district (Karen) approached her and indicated that teachers needed even more professional development in this area. During lunch, two teachers - Lacy and Anthony - asked if they could speak about their personal and professional experiences with ASD as it relates to rurality. Both were teachers at another school in the district and parents to a young boy with ASD. They, too, asked for more assistance and resources. It was clear from these early conversations that parents and teachers had questions and concerns - not just about autism but also in regard to their access to resources and further education, as a direct result of being in a remote rural community. These conversations led us to question how the community and rural context influenced the overall experiences of students with ASD - as well as their parents, teachers, and service providers.

\section{Research Site}

The site of this study is a rural district in Appalachia, designated a rural remote district (the most remote) by the National Center for Education Statistics (NCES). Liberty County is located in a geographically isolated coalmining region situated deep into the mountain. "Stone," the county seat, has a population of 1,000 people (according to U.S. Census information). According to NCES data, Liberty County is a high poverty district with approximately $70 \%$ of students eligible for free and reduced lunch, with more than $85 \%$ eligible at one of the elementary schools at which we conducted 
Table 1

Participants

\begin{tabular}{llll}
\hline Name & Relationship to Study & Data & Years in Rural Community \\
\hline Alice & Kindergarten teacher & Questionnaire & 24 years \\
Arnold & Teacher and parent & Questionnaire & All his life \\
Casey & Inclusion teacher & Questionnaire & 48 years \\
Charlotte & Speech therapist & Questionnaire & All her life \\
Karen & Special education teacher & Questionnaire / Interview & All her life \\
Lacy & Teacher and parent & Questionnaire / Interview & All her life \\
Michelle & Parent & Questionnaire / Interview & 7 years \\
Stephanie & Physical education teacher & Questionnaire / Interview & 2 months \\
\hline
\end{tabular}

interviews and with these numbers increasing as the region continues to lose its coalmining industry.

\section{Participants}

As a follow-up to this initial conversation and using a snowball sampling technique, Amy asked Karen to assist in finding additional participants to interview. This technique was particularly appropriate for this study, as it gave the authors access to parents and teachers in Liberty County with whom Karen acted as a liaison, laying the initial foundation for trust and candor often not extended to "outsiders" to the rural community. Karen, a lifelong resident of Liberty County was a special education teacher at Mountain Laurel Elementary, one of five elementary schools in the county, and an active member of the Special Education Advisory Committee (SEAC). (Of note, Karen is now the principal at Mountain Laurel.) As such, she had the opportunity and an interest to assist with recruiting participants for this study. It is unclear how many teachers she invited and discussed the study with,

\section{Data Collection}

As noted, an online questionnaire and in-person interviews were the two primary sources of data used to capture the responses and perceptions of the participants. The online questionnaire was created by the authors to directly relate to the purpose of this study, and consisted of 18 open-ended questions. The majority of the questions were designed to broadly gauge participants' personal experiences with ASD, and served to orient the authors, specifically gathering information about participant backgrounds, credentials, and teaching experiences. Questions addressed how long the participants had lived in the area, the types of professional development and but five other participants consented and completed an online questionnaire created by the authors (see Appendix A) in addition to Karen, Lacy, and Anthony who are mentioned above. Of the eight participants, seven are teachers or professionals across three different schools in Liberty County, and one participant is a professional within the community. Additionally, three of the participants are parents of children with ASD.

The eight participants who completed the online questionnaire were invited to participate in in-person interviews, and both authors traveled to Liberty County to conduct 30-60 minute interviews with four interested participants. The four participants who agreed to be interviewed included Karen (an elementary level special education teacher), Lacy (a kindergarten teacher and parent of a child with ASD), Stephanie (a physical education teacher), and Michelle (a professional in the community and parent of a child with ASD). See Table 1 for participant information.

training opportunities available to them, and challenges and benefits for working with students with ASD. Toward the end of the survey, the questions moved away from orienting questions that could be appropriate for participants in either urban or rural settings, toward a more context-specific focus on rural areas. Specific questions $(14,15$, and 18) addressed participants' perceptions regarding how living in a rural area influences these experiences. Perhaps the most salient questions asked were: "How do you think living in a rural area influences the experiences for students with ASD?" (question 15) and "Please provide any additional thoughts you would like to share that might help us better understand the experiences of students with 
ASD living in rural communities" (question 18), which of all the questions asked, garnered the lengthiest responses from participants.

Originating from participants' descriptive responses to these questions and additional information they voluntarily provided, the authors then identified participants who expressed interest in in-person interviews and designed a list of semistructured follow-up interview questions based on areas of interest from the questionnaire. For example, Stephanie's questionnaire response revealed that she believed living in a rural community could be "harmful" to students. In the semi-structured interviews, we asked her to expand upon this belief, giving personal examples to aid clarification and understanding of the initial responses she provided, delving deeper into how her experiences with rurality and ASD shaped her perceptions.

Each interview began with a conversation aimed at orienting the participant to the context of the study and as a way to gain rapport. Interviews were guided by the semi-structured questions, and probes were used to delve deeper into the meanings of participant statements. Interviews were audio recorded and later transcribed by Mary, with lowlevel inferences made to limit pauses in speech (e.g., "like, you know") in order to aid understanding and later analysis.

\section{Data Analysis}

Inductive analysis furthered our understanding of the data generated from the questionnaires and interviews, and analysis occurred in two stages. During the first stage of analysis, we collected, reviewed, and considered participants' questionnaire responses. Each author read and reread responses to understand the perceptions and experiences of teachers and parents of students with ASD as they specifically related to the remote rural community. Independently, both authors made comments about participants' specific views to look for similar or dissimilar trends across general education teachers, special education teachers, and parents, and then met to discuss interpretations. With the exception of one participant highlighting benefits to living with ASD in a rural community, we each noted that the participants' provided somewhat unfavorable perceptions toward the educational opportunities and experiences available for children with ASD in Liberty County.

After discussing the questionnaire responses, the authors established a semi-structured interview protocol for each interviewee based on the specific questionnaire responses for each participant. These protocols were used to allow the participants to elucidate on ideas they provided in questionnaire, and provided open-ended questions aimed at exploring the participants' backgrounds and experiences with ASD. Then, both researchers met with the four participants in Liberty County for in-person, audio recorded interviews, which lasted approximately $30-$ 60 minutes each.

The second stage of data analysis began after the completion of the in-person interviews, and the researchers met to debrief the interview sessions and to share their initial perceptions and impressions from the interviews. Then, Mary transcribed the four interviews, and the data corpus was read holistically and then qualitatively coded for emergent codes by both authors (Charmaz, 2006). During the coding process, the themes were refined to better describe the data, and the authors employed the Constant Comparative method, continually returning to the data set to compare and revise initial codes that emerged at various stages throughout the analysis, and then aggregating them into more focused codes and themes (Charmaz, 2006; Strauss \& Corbin, 1998). For example, initially we noted a significant dependence on the school, which we recorded as an initial code. However, through continued analysis and constant comparative measures, we determined that this dependence was not necessarily because parents were uninvolved in their child's educational experiences but because they lacked knowledge and awareness for managing the symptoms of ASD and for accessing available resources that may assist their child. Whether parents were advocating for their children or not, their limited knowledge influenced the overall educational experience of the student.

Based on the analysis of questionnaires and interviews, three salient themes that speak to the relationship between rurality and ASD were identified (see Figure 1). These themes, accompanied by illustrative responses from participants, are discussed in detail in the following section. 


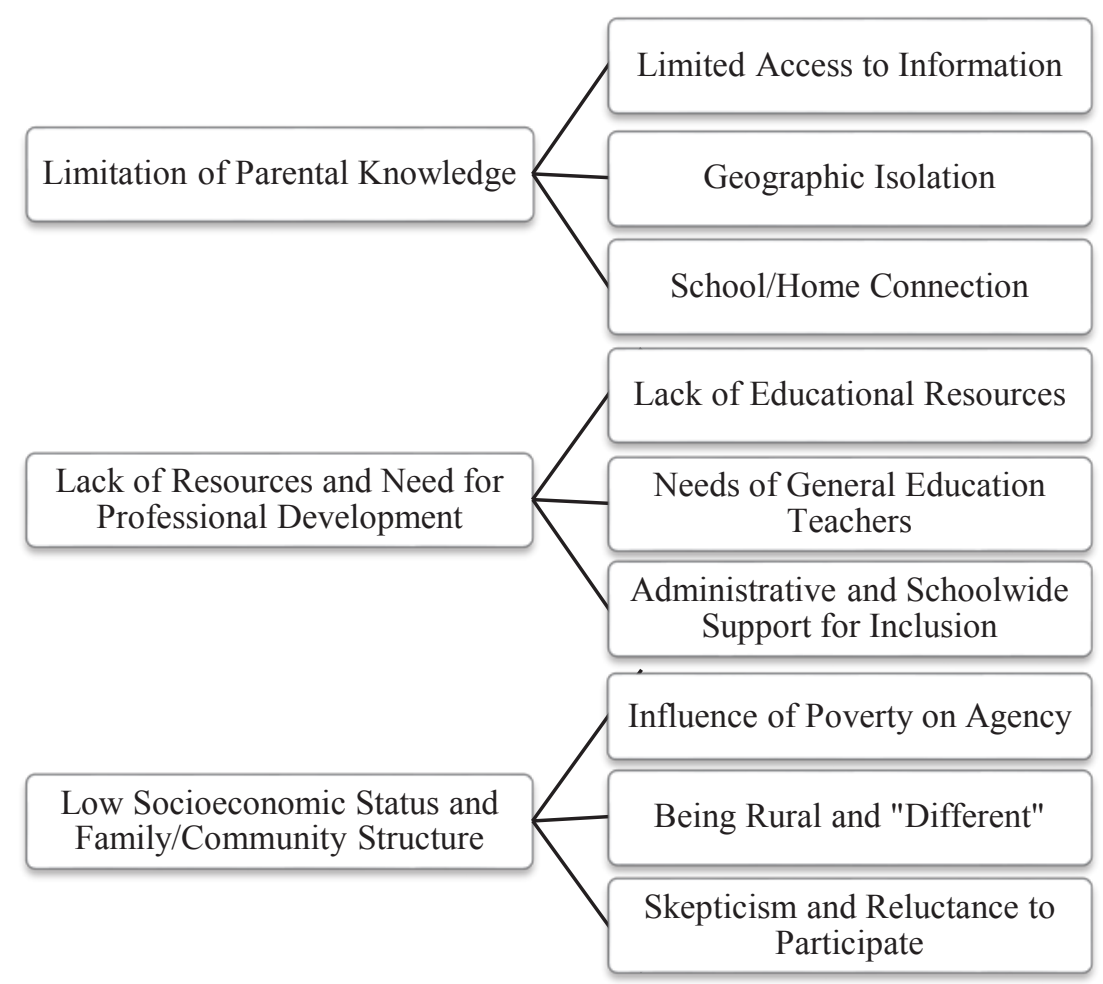

Figure 1. Diagram of Themes Generated from Participant Interviews and Questionnaires.

\section{Findings}

In this study, we sought to understand the participants' perceptions of the educational experiences for students with ASD from within the context of a remote rural community. Our data collection consisted of two phases of analysis, which included a questionnaire and follow-up, in-depth interviews with half of the participants. Our reading and rereading of the data corpus led to three salient themes. Themes were delineated according to family, school, and community factors, and included: (a) limitations of parental knowledge (family), (b) lack of resources and need for professional development (school), and (c) low socioeconomic status and family or community structure (community). Each theme is described below with illustrative quotes provided to support thematic understandings.

\section{Limitations of Parental Knowledge}

Within family structures, the theme of "limited knowledge" was pervasive throughout the study. From the questionnaire responses and interviews, participants expressed concern that many parents had limited knowledge and understanding of "what to do" to help their children with ASD, specifically in relation to living in a rural community. Parents raising children with ASD often gather information through the Internet, specialists, teachers, and trained personnel. In rural areas, however, these resources are limited and often inaccessible, which leaves parents of children with ASD often at a loss for how to navigate the educational process, and how to advocate for their child in general.

Limited access to information. Parent/teacher participant, Lacy, explained that many people within the community lack empathy for children with ASD because they have limited knowledge of the disability and its behavioral characteristics. Without awareness and information, parents are often unsure of how to manage a child that exhibits autistic characteristics, and often misidentify characteristics of ASD as behavioral problems, defining children with ASD as "kids that scream and throw fits." Lacy also noted that many people within the community lack education or "don't have Internet access or a computer," which limits their knowledge, because "If you don't read about it and study up, and expose yourself to knowledge, you aren't going to have the whole perspective on what to do."

Lacy felt that a lack of education led to a "communication breakdown" in which some of the parents knew "the ropes to follow" and "what to do," 
while other parents hoped or believed the autistic behaviors would simply "go away." When recalling a particular experience with a parent whose son has ASD, Lacy remarked, "I don't know if she thought he would come to school and just sort of grow out of it? Or if she didn't know quite what to do." Conversely, Lacy noted this lack of knowledge sometimes positions parents "on the defensive" when their child enters the school system, with parents afraid their child will be isolated and viewed as "special" by the general education teachers and other students. She recalled one parent who was concerned that the teachers would put her daughter "off to herself," or make her a "spectacle" for the other students.

Special education teacher, Karen, who often oversees the eligibility and identification processes for students with ASD, also discussed a lack of knowledge when talking to parents about ASD. Like Lacy, Karen explained that the outward signs of ASD are often viewed simply as defiant behaviors that should not be tolerated, and that parents simply do not understand ASD or what it means to be part of a special education program. She pointed out that parents come to Individualized Education Program (IEP) meetings and sign the papers, "but they still don't really know what that means for their child." Additionally, without parental awareness and support, Karen notes that it is difficult "for the child to make progress" academically:

You know when you think as a parent if that was your child, you would say, 'Okay, I'm going to a specialist. I'm going to see what this means for my child, and what I can do, and what I need to do, what kinds of services I start at a young age.' These people don't get that. You know, they don't know to do that. They don't know where to go to reach out to get extra services for their child, other than what they get here at school, so this is all they get. And if they aren't getting good things here, they are getting nothing.

Karen noted that this lack of parental understanding puts tremendous pressure and responsibility on the teacher to serve as an advocate for the student and family, as the teacher has "to try to not only take care of the needs of that child, but to kind of give some insight to the family too."

Geographic isolation. Lack of knowledge may be largely attributed to the limited Internet and phone access available within the area's mountainous, geographically isolated location. Lacy points out that living in Stone can make you feel "secluded in so many ways. We do not have the access to programs offered at facilities in urban areas, simply due to our rural location." While many areas take cell phone reception and high-speed Internet access as givens, and search engines such as Google are perceived by many as "lifelines" for learning about new resources and information on disabilities like ASD, Lacy points out that in Stone, the average $\$ 60$ per month for Internet is not a feasible option for individuals with limited means. Even for those fortunate enough to have a phone plan, access to $3 \mathrm{G}$ is limited. Residents are often forced to "drive five miles up the road" and waste limited data plans searching for cell phone reception "just trying to look up something."

In addition to lack of technological resources, geographic isolation and lack of access to transportation can also hinder the flow of information. When speaking about her experiences with parents, Lacy commented that "they are not going to be able to get the library because their vehicle is broke down, and if they don't have Internet at home," their access to information is limited at best. Lacy considered herself fortunate that she was able to afford Internet. However, she still empathized with her neighbors, close friends, and other community members and parents that do not have the necessary means to enjoy such a luxury.

School/home connection. Lack of awareness and geographic isolation also make it difficult for teachers to cultivate a connection between school and home that is necessary to help parents navigate the experience of raising and educating a child with ASD. Michelle, a paralegal who moved to Stone from an urban area, and who has a son with ASD in the school system, explained that her son's success rests solely in the hands of the special education teachers because there are simply no other available services. When speaking about her son, she said, "I can honestly say if it were not for two of Seth's special education teachers, I am not sure where we would be. I don't know if Seth would even have remained in the public school system."

As a kindergarten teacher, Lacy has the particularly unique challenge of helping parents whose children have not yet been diagnosed with ASD, and who are entering school for the first time. Having lived in the community her entire life, and having a son with ASD, she is often viewed by parents as a "lifeline" and invaluable resource toward understanding the disability. Often times, parents 
bring their child to school and view Lacy as their only source of information and help: "My personal experience has made this so much better with parents, because I have rapport with them, because I know, my kid needs this."

As a mother of a son with ASD, Lacy feels particularly responsible for advocating for her students and their parents. She believes her own, personal experiences with ASD give her a unique insider perspective into the struggles a parent faces when raising a child with ASD in a rural community. In particular, she talked about how her position gives her information and access to state resources available to rural schools that "If I wasn't a teacher at this school, and I'm just a Joe Blow person in the community with an autistic kid, I might not know everything I know because I didn't work here."

Having taught in Liberty County for four years, Karen remembers feeling "heartbroken" and saddened by the lack of inclusion and support within the schools. She worries about the students who leave her classroom and states, "There needs to be someone advocating for these kids." Karen notes that leadership is essential for bringing schoolwide or divisionwide inclusion, and that while change is needed, it should happen "a little bit at a time."

\section{Lack of Resources and Need for Professional Development}

Whereas the previous theme focused on the limitations of parental knowledge, this theme focuses on the lack of resources and the need for professional development at the school level. These two themes combine to explain the relationship between home and school in the context of rural communities and the experiences for students with ASD. On one hand, as described in this previous section, parents lack agency for knowing what to do and how to respond based on a variety of factors consistent with rural environments, such as limited Internet access. On the other hand, or possibly because parents lack a high level of knowhow, the onus on schools and teachers becomes even more pronounced, as explained in this section.

Lack of educational resources. One of the most prevalent challenges for raising a child with ASD in a rural community is the lack of resources available to these remote locations. Parents and teachers who are trying to advocate for students with ASD most acutely feel this disparity. Charlotte, a speech pathologist explained, "It is hard that we don't have additional resources for our students to enjoy. I would like to see our students with ASD be able to experience things and these events or places suited to their needs to help them enjoy it." Karen echoed these feelings, adding that the lack of funding not only places the students with ASD at a direct disadvantage, but also deprives the families of much needed resources and information. She said, "We also have limited resources in the school to purchase items that could help students or their families."

Similarly, Michelle points out that these issues extend into adulthood and that available resources are even more limited, putting even more pressure on the schools to provide parental and student support: "There's nothing here for the kids, so school is really just the thing. It's huge, huge." Michelle admitted that while living in a rural area does provide her family with some "advantages of a small town with the care," she also very passionately identified a lack of resources as "the most alarming and saddest part of raising a child with ASD in a rural community." Similarly, Karen recounted her past experiences with special needs students, lamenting that the lack of vocational opportunities in Stone make it "difficult to provide support to parents in our area because there are no local agencies that are available to help parents with the challenges of ASD."

While Karen noted that there are vocational opportunities nearby, the cost of such programs is often out of reach for families living in Stone who "don't have that kind of money for that." She also pointed out that the types of jobs they offer such as computer programming are "unrealistic" for students who have not been afforded many opportunities with technology, which points to a need for "vocationaltype jobs for kids who might not go on to college but are great, and good workers."

Needs of general education teachers. While participants did not understate the instrumental role of the schools in supporting students with ASD, the feeling was juxtaposed against a prevailing impression that even general education teachers lacked knowledge about ASD. For example, Karen explained that she has heard general education teachers repeatedly claim that students with ASD are "faking" symptoms in order to get out of doing work. Other participants gave similar personal examples of times when general education teachers were unaware of characteristics of ASD, and like some parents, 
often, mistook symptoms as behavioral problems or defiance that they felt should be swiftly dealt with.

As a neurological disorder, ASD typically has no obvious, outward traits other than behaviors. Casey, who co-teaches in an inclusion classroom, and completed the online survey but was unable to meet for an in-person interview, explained that general education teachers often find it difficult to identify with students with ASD and their specific needs because they look so "normal." She explained that she has worked with many teachers who believe the characteristic behaviors of ASD can be controlled:

I have had teachers tell me that they can't believe this or that child has ASD because he/she looks so normal. I also find it challenging working with others who think that students with ASD can control the outbursts or anxiety.

Similarly, Karen recalled a professional development training she conducted for the staff, in which she addressed the "fair versus equal concept." While she was unsure if her words were embraced, she believes this is one of the biggest hurdles for the teachers in Stone: "I think they are caught up in keeping everything equal, instead of fair. And that's a challenge. We are hung up on that." In a separate interview, Lacy also noted: "It's not about what's fair, it's about what's equal. It may not be fair, but it's what is needed."

Michelle echoed this sentiment, stating that while she supports inclusion, her experience is that general education teachers lack knowledge for meeting the needs of students with disabilities. This lack of teacher knowledge and training was most evident for her during her son's IEP meetings, in which she felt she had to "fight" for her son to receive the necessary and legally mandated accommodations for academic success. She pointed out that while rural areas can provide a caring, secure culture, and home life, the "downside of that is, I think, education for the teachers." This lack of education, according to Michelle, well-meaning, but untrained teachers attempting to "fix" her son's behaviors, instead of following his IEP. While Michelle believes that most teachers have good intentions, she noted that continuing training and education on the characteristics and behaviors of ASD should be used to rectify lack of teacher awareness and knowledge. However, even the best of intentions can be harmful if not executed correctly and in accordance with the appropriate knowledge and training; a sentiment Lacy knows all too well from repercussions her son has faced from wellmeaning teachers who did not understand the neurological nature of ASD.

Increasing the opportunities for professional development, training, and accessible resources could address awareness for ASD for teachers in rural areas. However, for teachers living in Stone, access to professional development and workshops specifically aimed at understanding ASD often require extensive travel and out-of-pocket expenses. While many of the teachers in Stone, like Karen, are willing and financially able to attend these workshops, the proximity and cost of traveling outside of the district is often not a feasible option for all teachers working with students who have ASD. Karen felt that if teachers lived in more urban areas or areas near universities they could get the training they needed, stating: "We need more things here that are accessible to here that we can provide through the school, through programs, through organizations here."

Administrative and schoolwide support for inclusion. Even if the appropriate tools and resources were available in Stone, it is questionable whether or not experienced teachers, who are familiar with more traditional pedagogical practices, would be willing to adapt their teaching for students with ASD. As Karen points out, "Some of the biggest battles have been over the silliest little things," and often, teachers are hesitant to embrace new changes, especially when these changes must be continually modified and adapted from day-to-day. When asked about this perceived lack of teacher knowledge and access to information about ASD, Karen stated:

The biggest challenge is the variance between each child and misconceptions from other teachers about students with ASD. Problem solving for each individual is a slow process that takes careful consideration as the 'wrong' tools might take you back a few steps. General Education Teachers do not always understand disabilities they cannot see and sometimes have a hard time with behavioral accommodations and support for anxiety. This has been the biggest struggle for me. It is hard to put a plan in place for a child and have setbacks due to other team members not being consistent with the plan or understanding the importance of following the plan precisely in order to maintain the routine. 
Conversely, Stephanie, a teacher with professional training in adaptive physical education at a school for ASD, entered Stone with a specific skill set and the knowledge to accommodate and include her students with special needs. She corroborated the idea that teachers in Liberty County "don't have these tools, and I have even said, I can help you; I can show you things, it's not a big deal." According to Stephanie, teachers in Stone not only lack tools, but also lack the desire for acquiring and implementing them. This resistance from more veteran teachers who seemingly did not want "to put in the extra effort" frustrated her. She said, "They need more training in these areas, and then maybe-I think it is just the comfort zone. You know, for whatever reason, these kids scare them, and they don't know how to adjust their curriculum or use the tools so that it's easier on these kids." As a special education teacher and outspoken advocate for her students, Karen has also witnessed this resistance first-hand, particularly when working with the general education teachers. She explained that when teaching children with ASD, too often teachers just "pass them from grade to grade" or try to "keep the class calm," rather than see the potential of special education students. While articulating this issue, Karen shared an experience she had with a particular student who she met outside the school building every morning, in which "some days were good and some days were very, very bad." Other teachers accused her of "babysitting" the student and not understanding the child's overwhelming anxiety-a characteristic of that student's ASD. Karen worked with the student closely all year with the goal of supporting him academically so that he could be successful on end of year assessments, and was thrilled when her consistent work paid off and the student was able to pass last year's state standardized tests.

Karen explained that because of that success, this school year has been easier for her. She said the general education teacher "realized that we had the same goal. We really did have the same goal at the end. And it may seem that I'm 'babying' the students, but my expectations are through the roof for them, because I know they can." However, in order for those high expectations to be met, Karen points out that she first has to get the child safely and comfortably into the building. She knows he will not be successful academically "if we don't meet these needs. And trying to get them [other teachers] to see that is the biggest I think hurdle that we have. And that's what we have to work on. And it has to come from leadership."

Karen, who is now actively seeking leadership positions within the school system in order to engender such change for her students, believes that real change comes from the top, not the bottom, because "I am the bottom. I am a teacher. You can't solve things from the bottom." Part of that change, according to Karen, is convincing people that ASD in rural contexts is an issue and a priority. She added that if other teachers "really bought into it...then as soon as they started seeing the positive impact and results, it would grow and flourish, and then we would really be making headway. Not just for those students, all the students, I mean they would all benefit."

\section{Low Socioeconomic Status and Family/Community Structure}

During the interviews, participants were quick to emphasize the positive aspects of living in a tightknit, rural community, but these advantages were also juxtaposed with the limitations of living in a geographically isolated area. In Stone, community structures and low socioeconomic status of families were two prevailing issues. Charlotte, a speech pathologist, pointed out on her questionnaire that living in a small community gives community members "more sense of safety and security. Families know one another and watch out for each other." Similarly, Michelle pointed out, "This is a very different place. I don't think you could ever meet people that have a better heart. It's a very strong community. But then on the flipside of it, I've never been anywhere that is as uneducated." This geographic isolation is compounded by the limited financial means of the population, which influences transportation and access to information outside of the community.

Influence of poverty on agency. While the community consists of what Michelle called "simple, kind folk," she perceives a de-emphasis on the importance of education, possibly due to the community's reliance on the coal industry and the fact that many students drop out of school to full-time job opportunities in the coalmines. The availability of jobs and the town's location deep in the hollows prepositions many of the residents for jobs in the coal mining industry, an occupation that can be entered into with little to no post-secondary training. As such, education is often a lower priority than earning a 
living wage and providing for families, and the area faces additional challenges like substance abuse, drugs, and unemployment. Alice, a kindergarten teacher who completed our questionnaire but was unable to meet for an interview also pointed out, "We have older siblings raising younger siblings, greatgrandparents raising grandchildren, because the child's parent/parents are in jail. We have a lot of poverty in our area."

In addition to unavailable resources and difficulty accessing information in these geographically remote areas, the area's limited economy also hinders the amount of money that can be allocated to additional resources and tools. Anthony, a fifth grade inclusion math teacher who has lived in Liberty County his entire life described Stone as "economically depressed," with limited "opportunities to succeed" due to lack of resources. Similarly, Charlotte explained:

A big challenge is that there is not enough money to be able to purchase more materials. I also have to purchase materials for my other students who do not have ASD. So with the amount I receive I have to try to purchase items for all my speech students. It would be great to be able to purchase more for my students with ASD.

Conversely, as a physical education teacher Stephanie felt that living in a rural area with low socioeconomic status actually placed her at an advantage when compared to more urban areas, because donors were willing to provide grants and funding to help assist students living in these underrepresented areas. However, she also pointed out that the mountainous geography in the area also hinders the students' ability to participate in activities because "living up in these hollers, there is no safe place to play or learn how to ride a bike," and often times, Stephanie perceived that parents are "too lazy or pathetic" to drive the students to a safer area where they can play.

Because of these economic disadvantages, Stephanie has been able to reach out to more prominent figures in the community to request many resources and materials for her adaptive physical education classes that she and her students would not otherwise have access to, such a tennis materials and bicycles for students with special needs. For Stephanie's adaptive PE class, the community support and acquisition of needed resources have made all the difference to her students and have allowed her to help them mitigate the gap from being an "outsider" or bystander in gym class to receiving the services and accommodations necessary to allow them to be active participants in an inclusive setting. Acquiring these needed resources for her adaptive PE class has allowed Stephanie to better advocate for her students in ways that the parents have been unable to in the past, and has provided her students with activities that they would not otherwise have access to.

Being rural and "different." The majority of Stone's population consists of people who have lived their entire lives there, and the community contains many extended family members and close-knit circles. However, while these secluded areas provide support and care for the community members, they also limit the amount of information and innovative ideas that flow into the community. Stephanie pointed out that many of the traditions and values of the community lead to a perpetuating of more narrow ideals concerning people and activities that are different, and she compared living in Stone to "living in the dark ages." She noted that the culture is rooted in conservative tradition and the people are passionate about what they believe in, but being viewed as "different" casts students "as an outsider with little chance of ever fitting in" with the community. She found that some of these rooted beliefs pose a unique set of challenges for students with ASD who are viewed as different, and who are labeled "outsiders" due to the lack of community knowledge and experience with ASD.

Stephanie's critical evaluation of Stone is likely influenced by her experiences in a more progressive area of expertise and training in special education. She emphasized that there are very few available activities for students to participate in after school, because "If you have a disability, you are just kind of, out there on the outside." Stephanie recalled sending out a parent survey toward the beginning of the year that asked, "What are your dreams for your child, what are your hopes?" She said the parents "didn't have anything, you know, and it just broke my heart, because I'm like, do they have a disability, yes, but they can still achieve, they can still be successful, they can still participate." However, the growing number of students diagnosed with ASD, the characteristic differences in behavior, and the need to accommodate educational techniques and community activities within a more inclusive setting present a challenge for many. 
Stephanie noted that living in a rural setting could be "harmful" for students with ASD because they are not afforded many opportunities outside of school for positive social interactions, and parental support at home is "practically nonexistent." Additionally, she worries that a lack of education and the fear of those who are different lead locals to view children with ASD as "taboo," and she worries that these students are "getting left behind and becoming more isolated than ever," as there are few advocates willing and able to fight for their children or show support. This lack of awareness and knowledge appears to culminate into a culture of the "insider" or normally functioning students and adults versus the "outsider," or students with ASD or special needs in general, that have been overlooked by their general education teachers and classmates.

\section{Skepticism and reluctance to participate.}

Even when teachers try to advocate for their students with ASD, this advocacy is often met with skepticism, fear, and resistance, due to the lack of education and knowledge of the parents. When Karen invited a state resource to the school to provide training and tools for her students, she faced unexpected setbacks and resistance from the parents. She explained that getting parents "to agree to have people come in like that has been difficult." Additionally, a large challenge has been school attendance and consistency: "You know, we can work on anything, whatever comes to school todayI'm ready. But if he's not at school and we're gone three weeks, and come back, then we start over. We start over. We start over." Karen explained that many of her students live with their grandparents and that explaining resources to an older generation is challenging. Reflecting on bringing in external services, Karen said grandparents were skeptical about having outsiders "come in to watch. They would ask, 'Are they coming to my house?' And you have to go through, 'no, they will not come to your home.' They are worried and scared, it's different, and it's a little intimidating."

Stephanie, who relocated to the area from an urban one, has especially faced this suspicion and skepticism when trying to advocate for her students, as she is commonly viewed as an "outsider." Stephanie is energetic and enthusiastic about providing resources, but has struggled with what she believes is apathy and resistance to change on the part of the parents. She lamented, "There's just no community support, awareness." She explained that based on her graduate school program and other professional experiences, she could run a Special Olympics group or Challenger baseball team. However, she felt that community members and students discouraged her. She was told that others tried it, no one would participate, and that she would be wasting her time. She added, "There are so many kids with disabilities, that's not the issue. It's just, you know, that the parents don't want to come, or they're working, or they're not working and they're just too lazy. So it's definitely an uphill battle."

Stephanie referred to parents as "lazy" a few times during our interview, and we recognize she is viewing the community as (for lack of a better descriptor) an outsider. That said, she seemed more able to talk candidly about the community as an economically depressed area and, in her opinion, how poverty and a lack of parental knowledge and education have led to a sense of apathy among parents. She noted this is most readily seen in parents not attending IEP meetings or school activities. She explained, "A lot of the kids have bad home lives. I know some of the adaptive kids, I mean, you can smell very heavy smoke." She explained that one of her students is in a wheelchair and does not get the support he needs at home with his exercises and that his parents "never come to school." Conversely, she added that some parents are involved and that those students get "all the help they need because their parents are so involved, but they have to fight for everything."

\section{Discussion}

Findings from this study suggest that the difficulties faced by teachers, families, and students living with ASD in rural areas are pervasive. While studies suggest that early diagnosis and treatment of ASD are critical (Blane \& Borden, 2008), schools in rural areas and early educators like Lacy are often the first to identify students with ASD. This leads to late identification and diagnosis (Mandell, et al., 2005), which can delay the early treatment needed to promote the continued developmental growth (Blane \& Borden, 2008). Additionally, as the participants pointed out, schools are often the only agency that provides resources, interventions, and special services for these students and their families, yet schools in rural areas experience difficulties staffing and retaining special education teachers and specialists, which limit the programs and resources that are available in these areas (Pennington, et al., 2009). 
This study also reiterated the importance of securing special education services, IEP plans, and interventions immediately after diagnosis (Blane \& Borden, 2008; Chen, et al., 2008). However, many teachers like Karen and Stephanie point out that parents like Michelle must "fight" for every service they receive, while other parents simply do not know how to advocate for their children. Because of this lack of knowhow, teachers are often viewed as the only viable resource for parents who are raising children with ASD. However, special education shortages, geographic isolation, and lack of communication often make it difficult for teachers to cultivate lasting home and school connections as Jung and Bradley (2006) suggested.

Additionally, lack of educational and vocational resources place students with ASD at a disadvantage in rural areas. While schools in Liberty County embrace inclusive practices, lack of knowledge and professional development from general educators can hinder the progress and success schools have when serving as a resource for students and families of children with ASD (Syriopoulou-Delli, et al., 2012). Lack of tools, strategies, and professional development may also hinder the county's ability to recruit and retain qualified teachers (Pennington, et al., 2009) like Stephanie, whose urban background prepositions her as an "outsider." In addition, due to geographic isolation, community members often hold narrow, intolerant perceptions toward students who are different, or who have disabilities. This skepticism further impedes the flow of outside resources from state agencies, and again can hinder the connection between special education teachers and parents of children with ASD in rural areas (Jung \& Bradley, 2006).

Furthermore, the need for special education and general education teachers to receive further professional development and training in order to collaborate more effectively is also apparent (Syriopoulou-Delli, et al., 2012), especially to Michelle, who said it is the "cry of my heart - that general ed and special ed would come together."

Lack of education and training in rural areas limit the opportunities teachers and schools are afforded to successfully advocate for their students with ASD. Additionally, the participants also expressed worry that even if the schools embrace inclusion and work collaboratively to educate students with ASD, without the needed support from school leadership, change would be slow and minimal. This supports research suggesting that schoolwide, positive attitudes toward inclusion are a top-down, collaborative endeavor that must begin with individuals in positions of power, like school principals (Horrocks, et al., 2008).

However, participants also described the rural community as one full of caring people who could be ready and willing to advocate and embrace children with ASD if given the appropriate information and opportunities. Lacy explained that the attitude in Stone is not "shove them here, shove them there" but rather "help this kid." Moreover, the positive aspect of living in a rural area is "we are such a close, tightknit community, that everyone here genuinely cares" about these students. This supports Pennington et al.'s (2009) suggestion that rural areas may be able to work together in order to overcome challenges and provide quality services and support for children with ASD in rural areas if they are given the adequate knowledge and tools.

These difficulties elevate schools to heightened positions of responsibility and power within the rural community. In fact, schools may be the only place that serve and provide resources for student with ASD and their families in geographically isolated areas like Stone. However, as this study suggests, schools are not fully ready for this challenge, as they lack the necessary resources, informed teachers, and professional development opportunities needed to enable them to advocate successfully for these students. Leadership within these school systems must afford teachers opportunities to receive special training and education necessary to make them successful. Additionally, professional development should slowly ease teachers into new instructional methods and strategies in a nonthreatening way, so that teachers can actively and successfully advocate for students with ASD and their families as Stephanie suggested.

In conclusion, students with ASD must be given equal opportunities for succeeding in the classroom and community, but challenges associated with rural areas complicate this endeavor. While inclusion might not be the best fit for all students, Karen's responses indicate that she has seen success stories, but that more training is needed to meet student needs and raise the expectations and buy-in from general educators, parents, and school principals. As Karen suggests, "opportunities are limited and we need to do more work to advocate for the needs of these special students and ensure they receive the education they deserve." Perhaps the first step is to provide teachers with the support for more professional 
development so they can be better equipped to advocate for their students with ASD in rural areas.

\section{Implications and Future Research}

The overall thematic understandings of the data generated in this study point to an obvious need for advocacy for rural students with ASD. While the presented challenges of living in a rural location may seem problematic, these communities already have one of the greatest resources to begin advocacy and awareness within the community: the schools. Murphy and Ruble (2012) state, "Unlike medical and behavioral health care services, however, public education is the one single service system that all children with autism have access to regardless of geographic location, family income, and insurance status" (p. 4).

Repeatedly, the participants expressed that in rural areas, the schools and teachers are the only advocates for the students, but teachers are unequipped, and lack the resources and education to adequately fulfill this responsibility (Pennington et. al, 2009; Rude et al., 2005). In order to effectively fulfill the needed advocacy roles, teachers and administrators must be given more information, education, and training on how to teach children with ASD (Horrocks, et al., 2008; Syriopoulou-Delli, et al., 2012). This assertion was echoed by Lacy, who said:

Some of the teachers have people in their families, or if they have actually had an autistic kid in their classroom, they've kind of had a 'crash course' to learn. But, in general, the regular Ed teachers need more training.

Casey added that she would "love to raise awareness in our community and schools on ASD," arguing that if "teachers are going to teach students with ASD, then they should be required to meet certain criterion of training on ASD." She described a plan for professional development that would give general education teachers the same workshops that special education teachers receive. Stephanie echoed that if teachers are taught to work collaboratively and advocate for their students with ASD, that inclusion could be more widely accepted within the schools and overarching community. Furthermore, Karen expressed her desired to continue her education so that she can make a further positive impact in her local community: "This is where I have grown up, this is where my community is, this is my family, and I want to help these kids. These kids have no one, and we need to change that. It shouldn't be they have no one. It should be they have us."

This study points to the need for increased advocacy at the local, regional, and state levels for students with ASD. In order to address the needs of teachers, families, and students with ASD living in rural communities, agencies must understand how place and rurality influence these experiences. Any research design and interventions must be informed by the community's contextual influences, such as geographic location, access to information and technology, poverty level, community structures, and socioeconomic status.

Additionally, researchers may be able to draw on the close-knit, caring community culture and willingness to help in order to address and overcome place-specific challenges (Pennington et al., 2009). Such advocacy may help provide necessary, additional training for general education teachers and continued professional development for special educators in rural placements (Syriopoulou-Delli, et al., 2012). Similarly, strengthening relationships between universities and rural regions could help encourage the flow of information into these rural areas, which would provide much-needed resources for teachers and parents of students with ASD. Cultivating strong relationships with universities could further empower schools and teachers with the knowledge and resources to become an informed, primary source of advocacy for students with ASD in rural communities.

\section{Appendix A}

Online Questionnaire

1. In the space below, please include your name and best contact information (email and/or phone).

2. Are you currently teaching or working in the local school system?

3. Do you currently teach or provide educational services to one or more students with ASD?

4. If no to the first two questions, please describe your occupation.

5. If you are a classroom or special education teacher, please describe your teaching position.

6. How many years have you worked in this position?

7. Which certifications or endorsements do you currently hold? 
8. What is your role in working with students with ASD?

9. How many years have you worked with students with ASD?

10. Please describe any professional development/training you have had on the topic of ASD.

11. Please describe your experiences (both challenges and benefits) in working with students with ASD.

12. Where do you live (city/town/country)?

13. How long have you lived there?

14. Please describe your local (rural) community.
15. How do you think living in a rural area influences the experiences for students with ASD?

16. Would you be willing to meet face-to-face for a 20-minute interview?

17. Indicate times below that would work with your schedule.

18. In the space below, please provide any additional thoughts you would like to share that might help us better understand the experiences of students with ASD living in rural communities.
American Psychiatric Association (2013). Diagnostic and statistical manual of mental disorders, $5^{\text {th }}$ Ed. Arlington, VA: American Psychiatric Association.

Bates, B. R., Graham, D., Striley, K., Patterson, S., Arora, A., \& Hamel-Lambert, J. (2014). Examining antecedents of caregivers' access to early childhood developmental screening: Implications for campaigns promoting use of services in appalachian Ohio. Child Health Promotion, 15(3), 413-421.

Behringer, B., \& Friedell, G. H. Appalachia: where place matters in health. Preventing Chronical Diseases [serial online] 2006, October [2016, October 22]. Available from:

http://www.cdc.gov/pcd/issues/2006/oct/06_00 67.htm.

Biddle, C., \& Azano, A. P. (2016). Constructing and reconstructing the "rural school problem": A century of rurality and rural education research. Review of Research in Education, 40, 298-325.

Blane, K., \& Borden, G. (2008). The importance of early intervention for ASD. The Brown University Child and Adolescent Behavior Letter, 24(6), 1-7.

Centers for Disease Control and Prevention. (2015, February 26). Data and statistics. Retrieved from CDC:

http://www.cdc.gov/ncbddd/ASD/data.html

Charmaz, K. (2006). Constructing grounded theory: A practical guide through qualitative analysis. Thousand Oaks, CA: SAGE.

Chen, G. Y., Liu, G. Y., Su, W. G., Huang, S. L., \& Lim, K. M. (2008). Urbanicity-related variation in help-seeking and services utilization among preschool-age children with ASD in Taiwan.

\section{References}

Journal of ASD and Developmental Disorders, 38, 489-497.

Edwards, N. M., Gallagher, R A., \& Green, K. B. (2013). Existing and proposed child find initiatives in one state's part C program. Rural Special Education Quarterly, 32(1), 11-19.

ERIC Clearinghouse on Disabilities and Gifted Education (2001, April). Educating exceptional children: A statistical profile. Arlington, VA: The Council for Exceptional Children.

Haverson, J., Ma, L., Harner, E. J. (2004). An analysis of disparities in health status and access to care in the Appalachian region. Washington (DC): Appalachian Regional Commission; 2004. Available from: http://www.arc.gov/index.do?nodeId=2467\&pri $\underline{\mathrm{nt}=\mathrm{yes}}$

Horrocks, J. L., White, G., \& Roberts, L. (2008). Principals' attitudes regarding inclusion of children with ASD in Pennsylvania public schools. Journal of ASD and Developmental Disorders, 38(8), 1462-1473.

Hutton, A. M., \& Caron, S. L. (2005). Experiences of families with children with autism in rural New England. Focus on ASD and Other Developmental Disabilities, 20(3), 180-189.

Iringa-Bistolas, C, Schalock, M., Marvin, R., \& Beck, L. (2007). Bridges to Success: A developmental induction model for rural early career special educators. Rural Special Education Qtiarterly, 26(1), 13-22.

Johnson, J., Showalter, D., Klein, R., \& Lester, C. (2014). Why Rural Matters 2013-2014: The Condition of Rural Education in the 50 States. Rural School and Community Trust. 
Jung, L. A., \& Bradley, K. D. (2006). Special education services in rural schools: A study of the kindergarten population using the EGLS-K. Rural Special Education Quarterly, 25(4), 25-30.

Kiani, R., Tyrer, F., Hodgson, A., Berkin, N. \& Bhaumik, S. (2013). Urban-rural differences in the nature and prevalence of mental ill-health in adults with intellectual disabilities. Journal of Intellectual

Disability Research, 57(2), 119-127. DOI: 10.1111/j.1365-2788.2011.01523.

Lauritsen, M. B., Astrup, A., Pedersen, C. B., Obel, C., Schendel, D. E., Schieve, L., Yeargin-Allsopp, M., \& Parner, E. T. (2014). Urbanicity and autism spectrum disorders. Journal of Autism and Developmental Disorders, 44(2), 394-404.

Mandell, D. S., Novak, M. M., \& Zubritsky, C. D. (2005). Factors associated with age of diagnosis among children with autism spectrum disorders. Pediatrics, 116(6), 1480-1486.

Murphy, A., \& Ruble, L. A. (2012). A comparative study on rurality and urbanicity on access to and satisfaction with services for children with ASD spectrum disorders. Rural Special Education Quarterly, 31(3), 3-11.

Pennington, R., Horn, C., \& Berrong, A. (2009). An evaluation of the differences between big city and small town special education services for students with low incidence disabilities in Kentucky. Rural Special Education Quarterly, 28(4), 3-9.
Pennington, R., Grau, R., Bobo, J., Lorence, D., Tomcheck, S., Stewart, J., \& Wooldridge, D. (2013). Building Statewide Support for Kentucky Families of Individuals with ASD. Rural Special Education Quarterly, 32(2), 3 .

Rude, H., Jackson, L., Correa, S., Luckner, J., Muir, S., \& Ferrell, K. (2005). Perceived needs of students with low-incidence disabilities in rural areas. Rural Special Education Quarterly, 24(3), 3-14.

Strauss, A., \& Corbin, J. (1998). Basics of qualitative research: Techniques and procedures for developing grounded theory. (2nd ed.). Thousand Oaks, CA: SAGE.

Syriopoulou-Delli, C. K., Cassimos, D. C., Tripsianis, G. I., \& Polychronopoulou, S. A. (2012). Teachers' perceptions regarding the management of children with ASD spectrum disorders. Journal of ASD and Developmental Disorders, 42(5), 755-768.

U.S. Census (2014) Table GCT1810: Percent of people with a disability. Retrieved from http://factfinder.census.gov/faces/tableservi ces/jsf/pages/productview.xhtml?pid=ACS _13_1YR_GCT1810.US01PR\&prodType $=$ table

Williams, J. G., Higgins, J. P. T., \& Brayne, C. E. G. (2006). Systematic review of prevalence studies of autism spectrum disorders. Archives of Disease in Childhood, 91(1), 8-15. doi: 10.1136/adc.2004.062083

\section{About the authors:}

Amy Price Azano is an Assistant Professor of Adolescent Literacy at Virginia Tech. Her scholarship focuses on rural literacies and opportunity gaps for rural students. She is an affiliate faculty member with the Virginia Tech Center for Autism Research through which she founded and coordinates SAFE: Supporting Autism Friendly Environments.

Mary Elizabeth Tackett is an Assistant Professor of Education at Sweet Briar College. Her research addresses underserved and marginalized populations within the context of literacy, with a particular focus on how children's books provide a context for learning about diversity and difference.

\section{Acknowledgements}

The authors wish to thank the Virginia Tech Center for Autism Research for funding support to conduct this research. 